\title{
Comentarios a "Utilidad del índice de resistencia obtenido por ultrasonido Doppler en nódulos tiroideos de características ecográficas malignas"
}

\author{
José Francisco Gallegos-Hernández \\ Instituto Mexicano del Seguro Social, Centro Médico Nacional Siglo XXI, Hospital de Oncología, Ciudad de México, México
}

Señores editores:

Me permito enviar la presente carta al con el objetivo de comentar el artículo "Utilidad del índice de resistencia obtenido por ultrasonido Doppler en nódulos tiroideos de características ecográficas malignas" de Butrón-García et al., publicado en el número 2 de 2018, páginas 161-164, volumen 154, de Gaceta Médica de México.

La finalidad de la investigación que se describe en el artículo fue conocer el valor del índice de resistencia de un nódulo tiroideo determinado en ultrasonido para identificar cáncer tiroideo.

Aunque el título precisa que se trata de "nódulos ultrasonográficamente sospechosos", esto no se concreta en el apartado Método ni se mencionan las características ultrasonográficas para considerarlos sospechosos, aspecto importante porque si los hallazgos ultrasonográficos indicasen que se trata de nódulos de sospecha podría saberse si el índice de resistencia por sí mismo tiene un valor independiente a los hallazgos ya conocidos.

Los autores, además, no precisan si la correlación se efectuó con el producto de la tiroidectomía, esto es, si todos los pacientes fueron llevados a cirugía o si el estándar de oro fue la citología obtenida por la biopsia por aspiración con aguja fina, información fundamental porque si la comparación es con citología, el valor del índice de resistencia es aún menor ya que no se tendría la certeza del diagnóstico verdadero.

Suponiendo que esta comparación haya sido efectuada con el producto de la tiroidectomía, es importante mencionar que este parámetro (el índice de resistencia) tuvo en la serie un índice de falsos-positivos de $38 \%$ y de falsos-negativos de $10 \%$, de tal manera que a más de un tercio de los pacientes se le dejaría de puncionar si la biopsia por punción se indicase solo con base en el índice de resistencia del nódulo. Al parecer, el verdadero valor de este hallazgo ultrasonográfico radica en que $86.6 \%$ de los pacientes con un índice bajo no tendrá cáncer tiroideo y en ellos se podría, eventualmente si no existe otra indicación ultrasonográfica, evitar la biopsia por punción guiada por ultrasonido.

El índice de resistencia no tiene un valor agregado al ultrasonido de alta resolución en la evaluación del nódulo tiroideo y actualmente no se considera un parámetro por evaluar durante el estudio ecográfico de un tumor de la glándula tiroides; las guías de la American Thyroid Association no lo incluyen como una medición ni como un posible hallazgo de riesgo de cáncer de tiroides; no permite indicar o descartar punción o cirugía, objetivo de la evaluación ultrasonográfica de un nódulo tiroideo.

Los hallazgos ultrasonográficos aceptados y que se relacionan estrechamente con la posibilidad de malignidad en nódulos tiroideos sólidos hipoecogénicos 0 parcialmente quísticos de $1 \mathrm{~cm}$ o más son márgenes irregulares, microcalcificaciones, mayor altura que ancho, calcificaciones del borde con proyección hacia tejidos blandos y evidencia de extensión extratiroidea; su presencia es considerada de alto riesgo para neoplasia maligna, con la que se asocian entre 70 y $90 \%$, por lo que constituyen indicaciones de punción o de tiroidectomía.

El índice de resistencia al no tener una adecuada relación con la histología no puede considerarse un indicador para efectuar invasión en un nódulo tiroideo, incluso, en nódulos con índice de resistencia bajo es la presencia de algunos de los hallazgos mencionados como de alto riesgo la que indicará si debe efectuarse una biopsia por aspiración con aguja fina guiada por ultrasonido o la escisión quirúrgica del nódulo.
Correspondencia: José Francisco Gallegos-Hernández E-mail: jfgalh61@gmail.com
Fecha de recepción: 13-05-2018

Fecha de aceptación: 21-05-2018 DOI://dx.doi.org/10.24875/GMM.18004402
Gac Med Mex. 2018;154:500-500

Disponible en PubMed

www.gacetamedicademexico.com 